\title{
Co-evolution of Leptospira and Tenrecidae (Afrotheria) on Madagascar
}

Yann Gomard ${ }^{1 \S}$, Steven M. Goodman ${ }^{2,3}$, Voahangy Soarimalala ${ }^{2}$, Magali $\operatorname{Turpin}^{1}$, Guenaëlle Lenclume $^{1}$, Marion Ah-Vane ${ }^{1}$, Christopher D. Golden ${ }^{4,5}$ and Pablo Tortosa ${ }^{1 *}$.

\section{Affiliations.}

${ }^{1}$ Université de La Réunion, Unité Mixte de Recherche Processus Infectieux en Milieu Insulaire Tropical (UMR PIMIT), CNRS 9192, INSERM 1187, IRD 249. Plateforme Technologique CYROI, Sainte Clotilde, La Réunion, France.

${ }^{2}$ Association Vahatra, BP 3972, Antananarivo 101, Madagascar.

${ }^{3}$ Field Museum of Natural History, Chicago, Illinois 60605-2496, United States of America.

${ }^{4}$ Department of Nutrition, Harvard TH Chan School of Public Health, Boston, Massachusetts 02115, United States of America.

${ }^{5}$ Department of Environmental Health, Harvard TH Chan School of Public Health, Boston, Massachusetts 02115, United States of America.

*Correspondence to pablo.tortosa@univ-reunion.fr

$\S$ Current address: Université de La Réunion, UMR PVBMT, F-97410, Saint-Pierre, La Réunion, France. 


\section{Abstract}

Leptospirosis is one of the most prevalent bacterial zoonoses in the world. The disease is caused by pathogenic Leptospira that are maintained in the kidney lumen of infected animals, mostly mammals, acting as reservoirs and contaminating the environment via infected urine. The investigation of leptospirosis through a One Health framework has been stimulated by notable genetic diversity of pathogenic Leptospira together with a high infection prevalence in certain animal reservoirs. Extensive sampling and associated microbiological and molecular studies of Madagascar's native mammal fauna have revealed a diversity of pathogenic Leptospira with high levels of host-specificity. Native rodents, tenrecids, and bats shelter a number of distinct lineages and species of Leptospira, some of which have also been detected in acute human cases. Specifically, L. mayottensis, first discovered in humans on Mayotte, an island neighboring Madagascar, was subsequently identified in a few species of Malagasy tenrecids, an endemic family. Distinct $L$. mayottensis lineages were identified in shrew tenrecs (Microgale cowani and Nesogale dobsoni) on Madagascar, and later in spiny tenrecs (Tenrec ecaudatus) on Mayotte. These findings suggest that L. mayottensis (i) has experienced co-evolutionary processes during the radiation of tenrecids on Madagascar, and (ii) has recently emerged in human populations on Mayotte following the introduction of $T$. ecaudatus from Madagascar. Hitherto, $L$. mayottensis has not been detected in spiny tenrecs on Madagascar. In the present study, we broaden the investigation of Malagasy tenrecids and describe the presence of L. mayottensis in Malagasy populations of T. ecaudatus, as well as in M. thomasi. These results confirm the hypothesis that L. mayottensis was introduced to Mayotte, presumably via T. ecaudatus, and provide additional data on the co-evolution of Leptospira and Tenrecidae.

Keywords: microbial endemism, Leptospira mayottensis, tenrecids, co-evolution, Madagascar, Mayotte, zoonoses 


\section{Introduction}

Leptospirosis is a zoonotic disease that results annually in around 100000 human cases and 58000 deaths (Costa et al., 2015). Pathogenic Leptospira are maintained in the lumen of the kidney tubules of animal reservoirs (Ristow et al., 2008), which can chronically shed viable bacteria in their urine and contaminate the environment (Adler, 2015). Although humans can be infected through direct contact with infected reservoirs, indirect transmission via contact with a contaminated environment during outdoor activities is most frequent (Ko et al., 2009). Infection leads to a wide range of symptoms ranging from mild flu-like syndromes to multi-organ failure causing death in $5-10 \%$ of the cases.

The genus Leptospira is currently composed of more than 60 species including saprophytic and pathogenic species (Adler 2015; Masuzawa et al. 2018; Thibeaux et al. 2018a; Thibeaux et al. 2018b; Vincent et al. 2019). Investigations carried out in different areas of the world on this genus of bacteria through a One Health approach have revealed distinct transmission chains composed of species or lineages and reservoirs that vary from one environmental setting to another (Bourhy et al. 2012; Cosson et al. 2014; Guernier et al. 2016; Biscornet et al. 2017; Guernier et al. 2017). Investigations carried out in the ecosystems of Madagascar and surrounding islands, hereafter referred to as the Malagasy Region, have provided new information on transmission chains on the different islands (Gomard et al., 2021). Indeed, while leptospirosis in humans is mostly caused by broadly distributed Leptospira that are likely of introduced origin on La Réunion and Seychelles (Biscornet et al., 2017; Guernier et al., 2016), Madagascar and Mayotte Island shelter distinctly more diversified Leptospira assemblages including species and lineages that can be considered endemic (Bourhy et al., 2010, 2012; Dietrich et al., 2014, 2018; Gomard et al., 2016; Tortosa et al., 2017).

Among pathogenic Leptospira described and investigated in the Malagasy Region, $L$. mayottensis, the principal focus of the current study, warrants further characterization. These bacteria were first isolated from human acute cases on Mayotte and initially named $L$. borgpetersenii group B (Bourhy et al., 2010, 2012). A thorough characterization of serological and genomic features of these isolates led the French Reference Center on Spirochetes to elevate this bacterium to the rank of a new species, which was named $L$. mayottensis in reference to the geographic origin of human isolates (Bourhy et al., 2014). A comprehensive investigation of the Malagasy wild mammal fauna allowed identification of 
Leptospira samples imbedded in the genetic clade of L. mayottensis and shed by two endemic small mammal species, namely Microgale cowani and Nesogale dobsoni (Dietrich et al., 2014). These two species belong to the endemic family Tenrecidae, composed of omnivorous small mammals known to play an important role in Leptospira maintenance as reservoirs of two distinct species: L. borgpetersenii and L. mayottensis (Dietrich et al. 2014; Dietrich et al. 2018; Dietrich et al. in press). The origin of the Tenrecidae, a monophyletic group, is the result of a single colonization event originating from Africa that took place 30$56 \mathrm{My}$ ago, followed by an extraordinary radiation leading to the currently known nearly 40 extant species or confirmed candidate species (Everson et al., 2016; Goodman et al., 2018). These findings strongly suggest that L. mayottensis has co-evolved with tenrecid hosts on Madagascar.

It has been proposed that L. mayottensis was introduced from Madagascar to Mayotte (Lagadec et al., 2016). This was supported by an investigation of animal reservoirs on Mayotte identifying Tenrec ecaudatus, a spiny tenrec introduced from Madagascar for human consumption, as the local reservoir of L. mayottensis. However, the hypothesis that T. ecaudatus sheds L. mayottensis currently suffers from a lack of evidence for Malagasy populations of this animal. In the present investigation, we screened T. ecaudatus specimens together with other tenrecid species sampled on Madagascar to broaden information on the presence of $L$. mayottensis in these animals, and to test the hypothesis of $L$. mayottensis introduction to Mayotte associated with that of T. ecaudatus. 


\section{Materials and methods}

\section{Ethical statement}

Biological sampling permits were obtained from the Ministry of Water and Forests and registered under the following numbers 20/16/MEEMF/SG/DGF/DAPT/SCBT.Re and 85/18/MEEF/SG/DGF/DSAP/SCB.Re.

\section{Biological sample}

All investigated shrew tenrecs were sampled in February 2016 in a forest neighboring the village of Anjozorobe, in the Central Highlands of Madagascar (see Figure 1). The samples included 31 specimens belonging to the following nine species: Microgale taiva $(n=15), M$. thomasi $(n=3), M$. majori $(n=3), M$. parvula $(n=2), M$. soricoides $(n=2), M$. cowani $(n=1), M$. longicaudata $(n=1), M$. fotsifotsy $(n=1)$, and Nesogale dobsoni $(n=3)$. All specimens were captured, manipulated, and euthanized following guidelines accepted by the scientific community for the handling of wild mammals (Sikes et al., 2011) and in strict accordance with permits issued by Malagasy national authorities (see ethical section). The spiny tenrec samples, Tenrec ecaudatus were composed of 24 specimens collected in villages adjacent to the Makira Natural Park in the Commune Antsirabe-Sahatany (Maroantsetra District) (Figure 1), an area with heavy human hunting pressure (Annapragada et al., 2021). All samples in this region were collected from captured animals and were provided by the hunters to the research team. All kidney samples from the collected animals from both project areas were removed and immediately stored in ethanol 70\% until DNA extraction and molecular analyses.

\section{Leptospira detection and sequencing}

For DNA extraction, kidneys were first rinsed with water and subsequently immersed in $2 \mathrm{~mL}$ of sterile water overnight. Then a thin transversal slice (approximately $0.5 \mathrm{~mm}$ thick) was cut in the central part of the kidney using a sterile scalpel, chopped in small pieces, and then immersed into lysis buffer provided in the DNeasy Blood \& Tissue Kit (Qiagen, Hilden, Germany) used for DNA extraction. All subsequent extraction steps were carried out following the manufacturer's instructions. Leptospira detection was then carried out on $2 \mu \mathrm{L}$ of eluted DNA using a probe-specific Real-Time Polymerase Chain Reaction system (RT-PCR) 
targeting a fragment of the 16S rRNA gene (Smythe et al., 2002). DNA templates leading to positive RT-PCR results were further subjected to an end-point PCR targeting the $\sec Y$ and adk loci as previously described (Dietrich et al., 2014). Amplicons were Sanger sequenced on both strands at Genoscreen (Lille, France) using the same PCR primers. The produced chromatograms were visually edited using Geneious software version 9.0.5 (Kearse et al., 2012).

\section{Phylogeny}

A phylogeny was constructed for the $\sec Y$ gene based on the bacterial sequences generated in the present study and previous secY sequences from other research in the Malagasy Region (Bourhy et al., 2012; Dietrich et al., 2014, 2018; Gomard et al., 2016; Lagadec et al., 2016) (Table S1). The best model of sequence evolution was determined with jModelTest v.2.1.4 (Darriba et al., 2012). Phylogenetic reconstructions were performed with MrBayes v.3.2.3 (Ronquist et al., 2012). The analyses consisted of two independent runs of four incrementally heated Metropolis Coupled Markov Chain Monte Carlo (MCMCMC) starting from a random tree. MCMCMC was run for 2 million generations with trees and associated model parameters sampled every 100 generations. The convergence level of each phylogeny was validated by an average standard deviation of split frequencies inferior to 0.05 . The initial $10 \%$ of trees for each run were discarded as burn-in and the consensus phylogeny along with posterior probabilities were obtained from the remaining trees. The resulting Bayesian phylogenies were visualized, annotated, and rooted to midpoint with FigTree v.1.4.2 (Rambaut, 2014).

\section{Results}

The detection by RT-PCR indicates a global leptospiral infection rate of $8.9 \%$ (4/45) with bacteria detected in three out of the nine tested tenrecids species: T. ecaudatus (1 positive specimen), $M$. thomasi (2 positive specimens), and $M$. taiva (1 positive specimen). The PCR protocols allowed leptospiral sequences to be obtained from the RT-PCR positive $T$. ecaudatus (sech) and from one out of the two RT-PCR positive M. thomasi (secY and adk). No bacterial sequence was obtained from the second RT-PCR positive $M$. thomasi or from the RT-PCR positive $M$. taiva. The three produced sequences were deposited in GenBank under the accession numbers: MT442041-MT442043. 
We present in Figure 1 the Bayesian phylogeny obtained from the $\sec Y$ gene, which includes four principal clades corresponding to L. borgpetersenii, L. mayottensis, $L$. interrogans, and L. kirschneri. Within this phylogeny, the bacterial sequences obtained from T. ecaudatus and $M$. thomasi fall in the L. mayottensis clade and form a well-supported subclade with a leptospiral sequence obtained from N. dobsoni. This subclade is related to one subclade of L. mayottensis detected in humans and tenrecs from Mayotte. All Leptospira sequences from Microgale and Nesogale species fall within two distinct clades: $L$. borgpetersenii and L. mayottensis. Interestingly, tenrecid species have been found infected by these two Leptospira bacteria, specifically $L$. borgpetersenii in $M$. longicaudata, $M$. principula and $M$. majori or L. mayottensis in M. cowani and $N$. dobsoni clades. Our results confirm this observation with the detection of L. mayottensis in M. thomasi and Malagasy populations of T. ecaudatus.

\section{Discussion}

The Tenrecidae are placental mammals grouped within a monophyletic and endemic Malagasy family composed of nearly 40 species, including confirmed candidate species (Olson 2013; Everson et al. 2016; Goodman et al. 2018). This highly diversified family is currently considered the result from a single colonization event originating from East Africa that took place between 30 and 56 My ago, followed by speciation that resulted in an exceptional adaptive radiation (Emerson, 2002; Krause, 2010). Some tenrecids exhibit a number of biological features unique among mammals, such as the ability of hibernating without interbout arousal, partial heterothermy or elementary echolocation (Lovegrove et al., 2014; Olson, 2013).

The long evolutionary history of the Tenrecidae also makes these mammals suitable for investigating the evolution of host-parasite interactions. Tenrecids host a diversity of Paramyxoviruses, some of which having experienced host switches with introduced murid rodents (Wilkinson et al., 2014). Tenrecidae are known to be hosts of two species of pathogenic Leptospira, namely L. borgpetersenii and L. mayottensis (Dietrich et al., 2014, 2018; Lagadec et al., 2016). While L. mayottensis has been essentially identified in tenrecids or acute human cases, a study on Madagascar reported the presence of L. mayottensis in introduced Rattus rattus but only as co-infections with other Leptospira species (Moseley et al., 2018). The strong host-specificity of L. mayottensis towards tenrecids was recently tested 
through experimental infection in which L. mayottensis isolated from T. ecaudatus failed to colonize the kidneys of $R$. norvegicus (Cordonin et al., 2020). The present study was carried out to (i) further explore the diversity of L. mayottensis sheltered by tenrecids and (ii) confirm a previous hypothesis that proposed L. mayottensis arrived on Mayotte with the introduction of T. ecaudatus for human consumption.

Analyzed samples confirmed tenrecids as being a reservoir of $L$. mayottensis and added $M$. thomasi to the list of animal reservoirs of this pathogenic bacteria. Most interestingly, we report the first characterization of L. mayottensis from T. ecaudatus on Madagascar. Together with previous data reported on Mayotte (Lagadec et al., 2016), the present work supports the introduction of this mammal species being associated with the emergence of a zoonotic pathogen, L. mayottensis, on Mayotte. Tenrec ecaudatus has also been introduced to other islands in the Malagasy Region with the purpose of providing bush meat, most notably La Réunion, Mauritius, Mahé (Seychelles), and other islands in the Comoros archipelago, but to our knowledge L. mayottensis has been not isolated in these non-native tenrec populations or reported in local human inhabitants.

The data presented herein also strongly support that $L$. mayottensis is an endemic zoonotic pathogen to Madagascar. It has been hypothesized nearly a century ago that the extreme abundance and unbounded dispersal capacities of microorganisms limit endemism to some extreme environments and that biogeographical patterns result from contemporary selective pressures rather than from limited dispersal capacity. This dogma, often referred to as Bass Becking hypothesis - "everything is everywhere but the environment selects" (Baas Becking, 1934) - has been challenged, and microbial biogeography is still in its infancy (de Wit and Bouvier 2006; Fierer 2008). The present study supports that host-specificity needs be considered as a driver of microbial endemism: the dispersal capacities of hostspecific microbes is indeed limited by that of their hosts. In other words, when considering host-parasite pairs, the dispersal capacities of hosts drive the biogeographical patterns of their associated microorganisms and may, in the case of strong host-parasite specificity, lead to microbial endemism. 


\section{Table and figure legends}

Figure 1. Geographical context and Bayesian phylogenetic tree of Leptospira species from Mayotte (blue) and Madagascar (green) based on secY gene (482 bp). The analysis was conducted under the $\mathrm{HKY}+\mathrm{I}+\mathrm{G}$ substitution model and the tree is midpoint rooted. Black circles at the nodes indicate posterior probabilities superior or equal 0.90 . The red stars indicate new sequences generated in the present study and were obtained from two regions on Madagascar: Anjozorobe and Antsirabe-Sahatany. The map was realized with the function worldHires from R package mapdata (Becker \& Wilks, 2018) under the R software version 4.1.1.

Table S1. Details on Leptospira secY sequences used in the present study: host families and species, geographical origins, Leptospira species and GenBank accession number. * Sequences generated in the present study.

\begin{tabular}{|c|c|c|c|c|}
\hline Host families & Host species & Islands & Leptospira species & $\begin{array}{c}\text { SecY GenBank } \\
\text { accession } \\
\text { number }\end{array}$ \\
\hline \multirow[t]{3}{*}{ Hipposideridae } & Macronycteris commersoni & Madagascar & Leptospira sp. & KP822608 \\
\hline & Macronycteris commersoni & Madagascar & Leptospira sp. & KP822609 \\
\hline & Macronycteris commersoni & Madagascar & Leptospira sp. & KP822611 \\
\hline \multirow[t]{8}{*}{ Hominidae } & Homo sapiens & Mayotte & Leptospira borgpetersenii & JN683935 \\
\hline & Homo sapiens & Mayotte & Leptospira borgpetersenii & JN683944 \\
\hline & Homo sapiens & Mayotte & Leptospira borgpetersenii & JN683945 \\
\hline & Homo sapiens & Mayotte & Leptospira interrogans & JN683938 \\
\hline & Homo sapiens & Mayotte & Leptospira kirschneri & JN683930 \\
\hline & Homo sapiens & Mayotte & Leptospira kirschneri & JN683932 \\
\hline & Homo sapiens & Mayotte & Leptospira kirschneri & JN683936 \\
\hline & Homo sapiens & Mayotte & Leptospira mayottensis & JN683931 \\
\hline \multirow[t]{9}{*}{ Miniopteridae } & Miniopterus griffithsi & Madagascar & Leptospira borgpetersenii & KP822628 \\
\hline & Miniopterus griffithsi & Madagascar & Leptospira kirschneri & KP822629 \\
\hline & Miniopterus mahafaliensis & Madagascar & Leptospira borgpetersenii & KP822630 \\
\hline & Miniopterus mahafaliensis & Madagascar & Leptospira borgpetersenii & KP822642 \\
\hline & Miniopterus mahafaliensis & Madagascar & Leptospira kirschneri & KP822640 \\
\hline & Miniopterus majori & Madagascar & Leptospira borgpetersenii & KP822650 \\
\hline & Miniopterus manavi & Madagascar & Leptospira borgpetersenii & KP822623 \\
\hline & Miniopterus manavi & Madagascar & Leptospira kirschneri & KP822622 \\
\hline & Miniopterus sororculus & Madagascar & Leptospira borgpetersenii & KP822651 \\
\hline \multirow[t]{2}{*}{ Molossidae } & Mormopterus jugularis & Madagascar & Leptospira sp. & KP822656 \\
\hline & Otomops madagascariensis & Madagascar & Leptospira sp. & KP822664 \\
\hline \multirow[t]{2}{*}{ Muridae } & Rattus rattus & Mayotte & Leptospira borgpetersenii & KT338849 \\
\hline & Rattus rattus & Mayotte & Leptospira interrogans & KT338838 \\
\hline Nesomyidae & Eliurus minor & Madagascar & Leptospira borgpetersenii & KF928130 \\
\hline Pteropodidae & Rousettus madagascariensis & Madagascar & Leptospira sp. & KP822667 \\
\hline
\end{tabular}




\begin{tabular}{ccccc} 
Rhinonycteridae & Triaenops menamena & Madagascar & Leptospira sp. & KP211750 \\
& Triaenops menamena & Madagascar & Leptospira sp. & KP822613 \\
& Triaenops menamena & Madagascar & Leptospira sp. & KP822616 \\
\hline Tenrecidae & Hemicentetes nigriceps & Madagascar & Leptospira kirschneri & KF928148 \\
& Microgale cowani & Madagascar & Leptospira mayottensis & KF928128 \\
& Microgale longicaudata & Madagascar & Leptospira borgpetersenii & KF928137 \\
& Microgale majori & Madagascar & Leptospira borgpetersenii & KF928124 \\
& Microgale majori & Madagascar & Leptospira borgpetersenii & KF928136 \\
& Microgale principula & Madagascar & Leptospira borgpetersenii & KF928121 \\
& Microgale principula & Madagascar & Leptospira borgpetersenii & KF928127 \\
& Microgale thomasi & Madagascar & Leptospira mayottensis & MT422042* \\
& Nesogale dobsoni & Madagascar & Leptospira mayottensis & KF928135 \\
& Nesogale dobsoni & Madagascar & Leptospira mayottensis & KT338848 \\
Nesogale dobsoni & Madagascar & Leptospira mayottensis & KT338850 \\
Nesogale dobsoni & Madagascar & Leptospira mayottensis & KT338851 \\
& Tenrec ecaudatus & Madagascar & Leptospira mayottensis & MT422041* \\
& Tenrec ecaudatus & Mayotte & Leptospira mayottensis & KT338858 \\
\hline Myotis goudoti & Madagascar & Leptospira borgpetersenii & KP822668 \\
& Myotis goudoti & Madagascar & Leptospira borgpetersenii & KP822673 \\
Myotis goudoti & Madagascar & Leptospira kirschneri & KP822672 \\
Laephotis robertsi & Madagascar & Leptospira sp. & KP822680 \\
\hline Vespertilionidae & &
\end{tabular}




\section{References.}

Adler, B. (Ed.). (2015). Leptospira and Leptospirosis. Springer-Verlag. //www.springer.com/gb/book/9783662450581

Annapragada, A., Brook, C. E., Luskin, M. S., Rahariniaina, R. P., Helin, M., Razafinarivo, O., Ambinintsoa Ralaiarison, R., Randriamady, H. J., Olson, L. E., Goodman, S. M., \& Golden, C. D. (2021). Evaluation of tenrec population viability and potential sustainable management under hunting pressure in northeastern Madagascar. Animal Conservation. https://doi.org/10.1111/acv.12714

Baas Becking, L. G. M. (1934). Geobiologie of Inleiding Tot de Milieukunde. W. P. Van Stockum \& Zoon.

Becker, R. A., \& Wilks, A. R. (2018). R version by Ray Brownrigg. Mapdata: Extra Map Databases (version 2.3.0). https://CRAN.R-project.org/package=mapdata

Biscornet, L., Dellagi, K., Pagès, F., Bibi, J., Comarmond, J. de, Mélade, J., Govinden, G., Tirant, M., Gomard, Y., Guernier, V., Lagadec, E., Mélanie, J., Rocamora, G., Minter, G. L., Jaubert, J., Mavingui, P., \& Tortosa, P. (2017). Human leptospirosis in Seychelles: A prospective study confirms the heavy burden of the disease but suggests that rats are not the main reservoir. PLoS Neglected Tropical Diseases, 11(8), e0005831. https://doi.org/10.1371/journal.pntd.0005831

Bourhy, P., Collet, L., Brisse, S., \& Picardeau, M. (2014). Leptospira mayottensis sp. Nov., a pathogenic species of the genus Leptospira isolated from humans. International Journal of Systematic and Evolutionary Microbiology, 64(Pt 12), 4061-4067. https://doi.org/10.1099/ijs.0.066597-0

Bourhy, P., Collet, L., Clément, S., Huerre, M., Ave, P., Giry, C., Pettinelli, F., \& Picardeau, M. (2010). Isolation and characterization of new Leptospira genotypes from patients in Mayotte (Indian Ocean). PLoS Neglected Tropical Diseases, 4(6), e724. https://doi.org/10.1371/journal.pntd.0000724

Bourhy, P., Collet, L., Lernout, T., Zinini, F., Hartskeerl, R. A., van der Linden, H., Thiberge, J. M., Diancourt, L., Brisse, S., Giry, C., Pettinelli, F., \& Picardeau, M. (2012). Human Leptospira isolates circulating in Mayotte (Indian Ocean) have unique serological and molecular features. Journal of Clinical Microbiology, 50(2), 307-311. https://doi.org/10.1128/JCM.05931-11

Cordonin, C., Turpin, M., Bringart, M., Bascands, J.-L., Flores, O., Dellagi, K., Mavingui, P., Roche, M., \& Tortosa, P. (2020). Pathogenic Leptospira and their animal reservoirs: Testing host specificity through experimental infection. Scientific Reports, 10(1), 7239. https://doi.org/10.1038/s41598-020-64172-4

Cosson, J.-F., Picardeau, M., Mielcarek, M., Tatard, C., Chaval, Y., Suputtamongkol, Y., Buchy, P., Jittapalapong, S., Herbreteau, V., \& Morand, S. (2014). Epidemiology of Leptospira transmitted by rodents in southeast Asia. PLoS Neglected Tropical Diseases, 8(6), e2902. https://doi.org/10.1371/journal.pntd.0002902

Costa, F., Hagan, J. E., Calcagno, J., Kane, M., Torgerson, P., Martinez-Silveira, M. S., Stein, C., Abela-Ridder, B., \& Ko, A. I. (2015). Global morbidity and mortality of leptospirosis: A systematic review. PLoS Neglected Tropical Diseases, 9(9), e0003898. https://doi.org/10.1371/journal.pntd.0003898 
Darriba, D., Taboada, G. L., Doallo, R., \& Posada, D. (2012). jModelTest 2: More models, new heuristics and parallel computing. Nature Methods, 9(8), 772. https://doi.org/10.1038/nmeth.2109

de Wit, R., \& Bouvier, T. (2006). "Everything is everywhere, but, the environment selects"; what did Baas Becking and Beijerinck really say? Environmental Microbiology, 8(4), 755-758. https://doi.org/10.1111/j.1462-2920.2006.01017.x

Dietrich, M., Gomard, Y., Cordonin, C., \& Tortosa, P. (In press). Leptospira bacteria in Madagascar. In The new natural history of Madagascar (S.M. Goodman). Princeton University Press.

Dietrich, M., Gomard, Y., Lagadec, E., Ramasindrazana, B., Le Minter, G., Guernier, V., Benlali, A., Rocamora, G., Markotter, W., Goodman, S. M., Dellagi, K., \& Tortosa, P. (2018). Biogeography of Leptospira in wild animal communities inhabiting the insular ecosystem of the western Indian Ocean islands and neighboring Africa. Emerging Microbes \& Infections, 7(1), 57. https://doi.org/10.1038/s41426-018-0059-4

Dietrich, M., Wilkinson, D. A., Soarimalala, V., Goodman, S. M., Dellagi, K., \& Tortosa, P. (2014). Diversification of an emerging pathogen in a biodiversity hotspot: Leptospira in endemic small mammals of Madagascar. Molecular Ecology, 23(11), 2783-2796. https://doi.org/10.1111/mec.12777

Emerson, B. C. (2002). Evolution on oceanic islands: Molecular phylogenetic approaches to understanding pattern and process. Molecular Ecology, 11(6), 951-966. http://www.ncbi.nlm.nih.gov/pubmed/12030975

Everson, K. M., Soarimalala, V., Goodman, S. M., \& Olson, L. E. (2016). Multiple loci and complete taxonomic sampling resolve the phylogeny and biogeographic history of Tenrecs (Mammalia: Tenrecidae) and reveal higher speciation rates in Madagascar's humid forests. Systematic Biology, 65(5), 890-909. https://doi.org/10.1093/sysbio/syw034

Fierer, N. (2008). Microbial biogeography: Patterns in microbial diversity across space and time. In: Accessing Uncultivated Microorganisms: From the Environment to Organisms and Genomes and Back (K. Zengler). ASM Press. USA.

Gomard, Y., Dellagi, K., Goodman, S. M., Mavingui, P., \& Tortosa, P. (2021). Tracking animal reservoirs of pathogenic Leptospira: The right test for the right claim. Tropical Medicine and Infectious Disease, 6(4), 205. https://doi.org/10.3390/tropicalmed6040205

Gomard, Y., Dietrich, M., Wieseke, N., Ramasindrazana, B., Lagadec, E., Goodman, S. M., Dellagi, K., \& Tortosa, P. (2016). Malagasy bats shelter a considerable genetic diversity of pathogenic Leptospira suggesting notable host-specificity patterns. FEMS Microbiology Ecology. https://doi.org/10.1093/femsec/fiw037

Goodman, S. M., Soarimalala, V., \& Olson, L. E. (2018). Systématique des tenrecs endémiques malgaches (famille des Tenrecidae) / Systematics of endemic Malagasy tenrecs (family Tenrecidae). In Les aires protégées terrestres de Madagascar: Leur histoire, description, et biote. / The terrestrial protected areas of Madagascar: Their history, description, and biota (S. M. Goodman, M. J., and S. Wohlhauser). Association Vahatra. 
Guernier, V., Lagadec, E., Cordonin, C., Minter, G. L., Gomard, Y., Pagès, F., Jaffar-Bandjee, M.-C., Michault, A., Tortosa, P., \& Dellagi, K. (2016). Human leptospirosis on Reunion Island, Indian Ocean: Are rodents the (only) ones to blame? PLOS Negl Trop Dis, 10(6), e0004733. https://doi.org/10.1371/journal.pntd.0004733

Guernier, V., Richard, V., Nhan, T., Rouault, E., Tessier, A., \& Musso, D. (2017). Leptospira diversity in animals and humans in Tahiti, French Polynesia. PLoS Neglected Tropical Diseases, 11(6), e0005676. https://doi.org/10.1371/journal.pntd.0005676

Kearse, M., Moir, R., Wilson, A., Stones-Havas, S., Cheung, M., Sturrock, S., Buxton, S., Cooper, A., Markowitz, S., Duran, C., Thierer, T., Ashton, B., Meintjes, P., \& Drummond, A. (2012). Geneious Basic: An integrated and extendable desktop software platform for the organization and analysis of sequence data. Bioinformatics (Oxford, England), 28(12), 1647-1649.

https://doi.org/10.1093/bioinformatics/bts199

Ko, A. I., Goarant, C., \& Picardeau, M. (2009). Leptospira: The dawn of the molecular genetics era for an emerging zoonotic pathogen. Nature Reviews. Microbiology, 7(10), 736747. https://doi.org/10.1038/nrmicro2208

Krause, D. W. (2010). Biogeography: Washed up in Madagascar. Nature, 463(7281), 613614. https://doi.org/10.1038/463613a

Lagadec, E., Gomard, Y., Minter, G. L., Cordonin, C., Cardinale, E., Ramasindrazana, B., Dietrich, M., Goodman, S. M., Tortosa, P., \& Dellagi, K. (2016). Identification of Tenrec ecaudatus, a wild mammal introduced to Mayotte Island, as a reservoir of the newly identified Human pathogenic Leptospira mayottensis. PLoS Negl Trop Dis, 10(8), e0004933. https://doi.org/10.1371/journal.pntd.0004933

Lovegrove, B. G., Lobban, K. D., \& Levesque, D. L. (2014). Mammal survival at the Cretaceous-Palaeogene boundary: Metabolic homeostasis in prolonged tropical hibernation in tenrecs. Proceedings of the Royal Society B-Biological Sciences, 281(1796), 20141304. https://doi.org/10.1098/rspb.2014.1304

Masuzawa, T., Sakakibara, K., Saito, M., Hidaka, Y., Villanueva, S. Y. A. M., Yanagihara, Y., \& Yoshida, S.-I. (2018). Characterization of Leptospira species isolated from soil collected in Japan. Microbiology and Immunology, 62(1), 55-59. https://doi.org/10.1111/1348-0421.12551

Moseley, M., Rahelinirina, S., Rajerison, M., Garin, B., Piertney, S., \& Telfer, S. (2018). Mixed Leptospira infections in a diverse reservoir host community, Madagascar, 2013-2015. Emerging Infectious Diseases, 24(6), 1138-1140. https://doi.org/10.3201/eid2406.180035

Olson, L. E. (2013). Tenrecs. Current Biology, 23(1), R5-R8. https://doi.org/10.1016/j.cub.2012.11.015

Rambaut, A. (2014). FigTree 1.4.2 software. Institute of Evolutionary Biology, University of Edinburgh. http://tree.bio.ed.ac.uk/ software/figtree/

Ristow, P., Bourhy, P., Kerneis, S., Schmitt, C., Prevost, M.-C., Lilenbaum, W., \& Picardeau, M. (2008). Biofilm formation by saprophytic and pathogenic leptospires. Microbiology (Reading, England), 154(Pt 5), 1309-1317. https://doi.org/10.1099/mic.0.2007/014746-0 
Ronquist, F., Teslenko, M., van der Mark, P., Ayres, D. L., Darling, A., Höhna, S., Larget, B., Liu, L., Suchard, M. A., \& Huelsenbeck, J. P. (2012). MrBayes 3.2: Efficient Bayesian phylogenetic inference and model choice across a large model space. Systematic Biology, 61(3), 539-542. https://doi.org/10.1093/sysbio/sys029

Sikes, R. S., Gannon, W. L., \& The Animal Care and Use Committee of the American Society of Mammalogists. (2011). Guidelines of the American Society of Mammalogists for the use of wild mammals research. Journal of Mammalogy, 92, 235-253.

Smythe, L. D., Smith, I. L., Smith, G. A., Dohnt, M. F., Symonds, M. L., Barnett, L. J., \& McKay, D. B. (2002). A quantitative PCR (TaqMan) assay for pathogenic Leptospira spp. BMC Infectious Diseases, 2, 13. http://www.ncbi.nlm.nih.gov/pubmed/12100734

Thibeaux, R., Girault, D., Bierque, E., Soupé-Gilbert, M.-E., Rettinger, A., Douyère, A., Meyer, M., Iraola, G., Picardeau, M., \& Goarant, C. (2018). Biodiversity of environmental Leptospira: Improving identification and revisiting the diagnosis. Frontiers in Microbiology, 9, 816. https://doi.org/10.3389/fmicb.2018.00816

Thibeaux, R., Iraola, G., Ferrés, I., Bierque, E., Girault, D., Soupé-Gilbert, M.-E., Picardeau, M., \& Goarant, C. (2018). Deciphering the unexplored Leptospira diversity from soils uncovers genomic evolution to virulence. Microbial Genomics. https://doi.org/10.1099/mgen.0.000144

Tortosa, P., Dellagi, K. M., \& Mavingui, P. (2017). Leptospiroses on the French islands of the Indian Ocean. Bulletin Epidémiologique Hebdomadaire - BEH, 8-9. https://hal.archives-ouvertes.fr/hal-01508690

Vincent, A. T., Schiettekatte, O., Goarant, C., Neela, V. K., Bernet, E., Thibeaux, R., Ismail, N., Khalid, M. K. N. M., Amran, F., Masuzawa, T., Nakao, R., Korba, A. A., Bourhy, P., Veyrier, F. J., \& Picardeau, M. (2019). Revisiting the taxonomy and evolution of pathogenicity of the genus Leptospira through the prism of genomics. PLoS Neglected Tropical Diseases, 13(5), e0007270. https://doi.org/10.1371/journal.pntd.0007270

Wilkinson, D. A., Mélade, J., Dietrich, M., Ramasindrazana, B., Soarimalala, V., Lagadec, E., Minter, G. le, Tortosa, P., Heraud, J.-M., Lamballerie, X. de, Goodman, S. M., Dellagi, K., \& Pascalis, H. (2014). Highly diverse Morbillivirus-related paramyxoviruses in the wild fauna of southwestern Indian Ocean islands: Evidence of exchange between introduced and endemic small mammals. Journal of Virology, JVI.01211-14. https://doi.org/10.1128/JVI.01211-14 


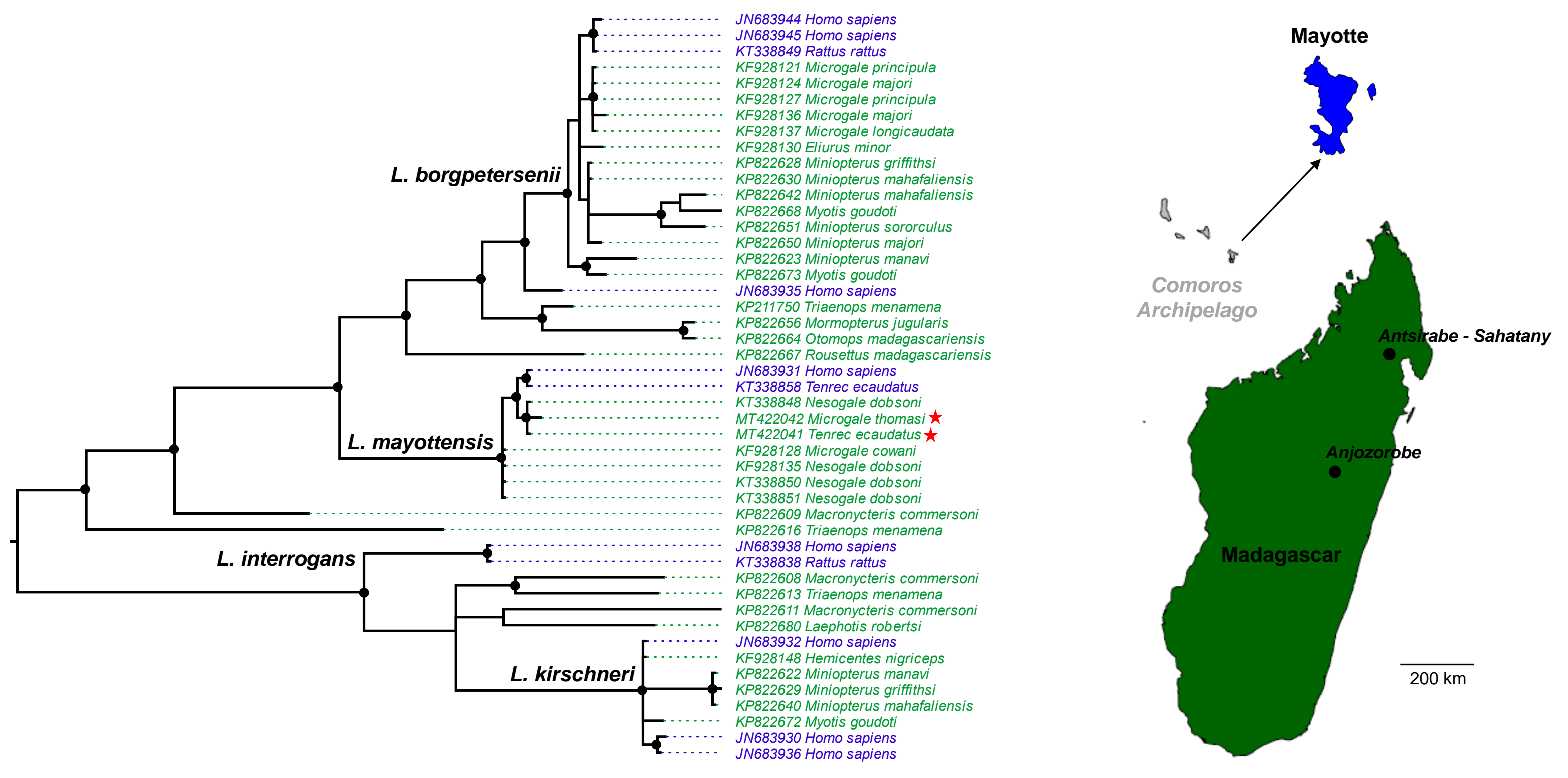

